\title{
Um sistema para a gestão econômica de organizações governamentais empreendedoras ${ }^{1}$
}

Revista do

Serviço

Público

Ano 52

Número 3

Jul-Set 2001

\author{
Armando Catelli, Cláudio Parisi, Edilene \\ Santana Santos e Lauro Brito de Almeida
}

\section{Introdução}

Em muitos países de economias de livre mercado, avançadas e emergentes, ${ }^{2}$ o Estado contemporâneo vem buscando nas últimas décadas superar as ineficiências da administração pública tradicional, tornada extremamente cara aos contribuintes, como já alertara Drucker (1978; 1989: 49-92). Para essa superação, os paradigmas de eficácia gerencial vêm sendo cada vez mais aplicados à gestão pública: o cidadão como cliente, a qualidade total a custos baixos nos serviços, governo orientado por missões e objetivos, descentralizado, preventivo, empreendedor, competitivo, voltado para o mercado - em suma, um governo por resultados (Osborne e Gaebler, 1995).

Esses autores constatam que nos Estados Unidos “os cidadãos de hoje se recusam a pagar altos impostos por serviços cujos preços disparam, enquanto a qualidade despenca"; "uma frustração crescente entre os contribuintes é não saber exatamente o que estão recebendo pelo dinheiro que investem" (Osborne e Gaebler, 1995: 152). Para superar essa frustração e convencidos de que "por não mensurar resultados, os governos burocratizados não logram grandes conquistas" (op.cit.: 151) programas locais, estaduais e federais americanos vêm adotando o "governo por resultados" fixando objetivos, metas e responsabilidades, combinadas com estratégias de avaliação e premiação por desempenho.

No Brasil, a postura do governo por resultados, incorporada no Plano Diretor da Reforma do Estado de 1995, vem sendo implantada nas diversas esferas governamentais que adotam a "reforma gerencial da administração pública" (Bresser Pereira, 2000: 18-28).

\footnotetext{
Armando Catelli é professor-doutor dos Programas de Mestrado e Doutorado em Controladoria e Contabilidade da FEA-USP.

Cláudio Parisi é mestre e doutor em Controladoria e

Contabilidade pela FEA-USP e professor da FECAP.

Edilene Santana Santos é mestre e doutoranda em Controladoria e Contabilidade pela FEA-USP e pesquisadora da FIPECAFI.

Lauro Brito de Almeida é mestre e doutorando em Controladoria e

Contabilidade pela FEA-USP.

Contatos: editron@ uol.com.br
} 
Tal como em outros países, também no Brasil, a eficácia do governo por resultados demanda sistemas eficazes de avaliação, seja por parte de órgãos controladores internos ao governo, seja por parte dos usuários da sociedade (op.cit: 24; Thoenig, 2000; Coutinho, 2000; Falco, 2000; Thompson, 2000). Tais sistemas, em geral baseados em indicadores físicos e qualitativos de desempenho e realização de metas, constituem experiência recente nos diversos países e seu estudo tem despertado grande interesse e discussão (Barbosa, 1996; Freitas, 1999; Thoenig, 2000; Campos et al., 2000).

Assim, financiamentos a programas de apoio aos desempregados são vinculados à proporção efetiva de empregos obtidos. Na ajuda habitacional, o financiamento se baseia na taxa de ocupação conseguida. Há experiências com avaliação de juízes e parâmetros de avaliação de tribunais inteiros. A construção de estradas, além dos materiais empregados, inclui agora a sua vida útil com multas ou prêmios aos empreiteiros (op.cit.: 153).

Entretanto, a mensuração do resultado das atividades governamentais apenas por índices físicos e qualitativos mostra-se insuficiente ao não incluir o parâmetro monetário de avaliação dos benefícios com o qual possam ser contrapostos os custos, ou seja, o sacrifício financeiro da sociedade via tributos. Por isso, a necessária expressão monetária dos benefícios gerados pela atividade pública e sua efetiva comparação com os custos torna, cada vez mais, a abordagem contábil-gerencial do "governo por resultados" uma abordagem da gestão pública como criadora de valor.

É sintomático que nos Estados Unidos a Junta Normativa da Contabilidade Governamental, que determina os padrões contábeis de governos estaduais e municipais, esteja redefinindo os “conceitos contábeis geralmente aceitos" para incluir critérios de avaliação de desempenho (op.cit.: 152).

Essa nova abordagem requer enfoques e instrumentos ainda pouco desenvolvidos nos sistemas contábeis gerenciais, mas que vêm sendo estudados pelo Sistema de Gestão Econômica ${ }^{3}$ e aplicados a organizações públicas no Brasil, no intuito de identificar e mensurar o valor criado nas diversas atividades da gestão pública.

O objetivo deste trabalho é expor esses conceitos, critérios e instrumentos que possibilitam a gestão econômica das organizações públicas como criadoras de valor. Será focada a criação de valor por uma entidade ou organização pública específica, como sua contribuição à atividade governamental. Fogem do escopo deste trabalho os enfoques da criação de valor tanto sob a ótica do governo como um todo, como sob a ótica da sociedade.

\section{Gestão pública por resultados}

Como se sabe, a recente redefinição do papel do governo em diversos países, inclusive no Brasil, ${ }^{4}$ se insere na evolução secular da administração pública (Bresser Pereira, 2000: 16-19). 
Na administração pública patrimonialista, predominante até o advento da Revolução Industrial, o Estado e seu aparato era uma extensão indistinta do poder do soberano, de sua família e da nobreza.

$\mathrm{Na}$ administração burocrática própria do Estado liberal, a gestão do Estado se incorpora em funcionários de carreira, para execução imparcial das políticas dos governantes eleitos rotativamente pelo povo. Entretanto, a burocracia estatal tende a perpetuar-se e a constituir um fim em si mesma, fixando-se em procedimentos formalistas de controle que geram ineficiência. Como observam Osborne e Gaebler (1995: 151), os governos burocratizados recompensam seus funcionários com base no tempo de serviço, no volume de recursos, no número de pessoas que administram e conforme sua posição na hierarquia. "Sendo assim esses funcionários tratam de manter seus empregos de qualquer maneira, construindo, assim, seus impérios, tentando conseguir orçamentos maiores, supervisionar mais funcionários e ter mais autoridade”.

Com as novas demandas de maior flexibilização da gestão pública em um mundo em mudanças tecnológicas aceleradas e em processo competitivo de globalização, desenvolveu-se, a partir da segunda metade do século XX, a chamada gestão pública empreendedora. Esta, voltada para a promoção econômica e para a satisfação das necessidades dos cidadãos, aplica parâmetros de eficácia e otimização empresarial e se caracteriza como uma "gestão por resultados". O "governo empreendedor", como observam Osborne e Gaebler (1995: 16), "emprega recursos de novas formas, para maximizar a produtividade e a eficiência".

No contexto da ineficiência e do crescimento excessivo do Estado fiscal burocrático, Drucker (1989: 61) já alertava que quase todos os países desenvolvidos, voltados para uma distribuição de renda via política tributária, já haviam chegado ao limite de carga fiscal proibitivo, além do qual - pelos efeitos da chamada "rebelião fiscal silenciosa" (apatia econômica, sonegação etc.) — há uma diminuição geral da própria receita fiscal e não um aumento. $\mathrm{O}$ autor constata que, conforme a Lei de Pareto, ${ }^{5}$ não é o aumento da carga fiscal que distribui a renda, mas sim o aumento da produtividade. Preconiza, assim, a volta à finalidade dos impostos de criar receitas com o mínimo de efeitos sócio-econômicos colaterais - para aplicá-las na promoção da produtividade como único meio de gerar riqueza, distribuir renda e corrigir as desigualdades sociais (op.cit.: 60-61).

Ao contrário da administração burocrática, fixada nos controles formais, que se "concentra excessivamente sobre as entradas, os recursos", a gestão empreendedora ${ }^{6}$ enfatiza o controle "sobre as saídas, os resultados" (Osborne e Gaebler, 1995: 150).

Como notam os autores, "qualquer instituição, pública ou privada, pode ser empreendedora, assim como qualquer instituição, pública ou 
privada, pode ser burocrática" (op.cit.: 23). Isso ocorre desde uma simples escola distrital (op.cit.:8ss) até a administração dos foguetes intercontinentais Minuteman no "arquétipo da burocracia", que é o Departamento de Defesa Americano (op.cit.: 11).

A reforma gerencial do Estado no Brasil considera que o núcleo estratégico, dentro das atividades exclusivas do Estado, não prescinde de certo enfoque burocrático (Presidency of Republic: 23; Bresser Pereira: 20). Isto, porém, não exclui que todas as organizações públicas admitam um enfoque de resultados, com avaliação econômica de suas atividades, pelo simples fato de consumirem recursos mensurados monetariamente em seus respectivos orçamentos - ainda que os respectivos benefícios nem sempre sejam fáceis de mensurar.

Por isso, um ponto de partida do governo empreendedor, como observam Osborne e Gaebler (op.cit.: 17ss), são as entidades voltadas para a gestão de atividades econômicas como energia, telecomunicações etc., nas quais é mais fácil identificar benefícios econômicos. Progressivamente, em um processo de aprendizagem (Thoenig, 2000: 58ss), inclusive com o desenvolvimento de dados empíricos (Campos et al., 2000: 39ss) amplia-se a abrangência e a eficácia da mensuração e dos sistemas de avaliação.

Um dos principais instrumentos dessa nova postura da gestão pública no Brasil são os contratos de gestão, ${ }^{7}$ que expressam o relacionamento principal-agente (Ramos, 1997: 88) entre o governo e suas organizações e entidades, particularmente as agências reguladoras ${ }^{8}$ (Bresser Pereira, 2000: 18ss; Campos et al., 2000), visando maior autonomia gerencial, com controle de resultados, para o melhor interesse da sociedade. Juridicamente, o contrato de gestão é um acordo firmado entre o governo e uma organização estatal com o fim de alcançar determinados objetivos em um determinado período (Lima et al., 1999: 548).

Os contratos de gestão visam, principalmente, a definição precisa de objetivos que o administrador público deve obter em sua unidade, assegurar a autonomia e a flexibilidade do administrador na gestão dos recursos humanos, materiais e financeiros para obter os fins contratados e, finalmente, o controle e a prestação de contas dos resultados obtidos (Presidency of the Republic, 1995: 21ss).

\section{Gestão pública e criação de valor}

Entre os objetivos fundamentais da administração pública do Brasil, inclui-se o desenvolvimento, a superação da pobreza e a promoção do bem comum (art. 3으 da Constituição Federal), ou seja a criação da riqueza ou valor. Esses objetivos se integram na linha de tendências atuais em sociedades avançadas, como a dupla agenda de "criar o crescimento 
econômico" e "integrar os pobres no processo de crescimento" das recentes administrações americanas e européias (Osborne, 1994: 11ss., 1ss).

A teoria econômica reconhece desde o início do século $\mathrm{XX}$ - a partir da distinção entre "economias internas" às empresas e "economias externas" ou setoriais desenvolvida por A. Marshall (1996: 359ss) e com a diferenciação entre social net product e private net product por A. C. Pigou (1962: 172-203) — que a administração pública, ao garantir, por exemplo, a segurança coletiva, a saúde pública, um meio ambiente renovável ou a concorrência nos setores econômicos, cria valor para a sociedade. O valor é criado pela atuação governamental, seja para superação das chamadas "externalidades negativas" ou "deseconomias externas" que dificultam a atividade econômica "interna" dos agentes individuais, como as empresas ou as pessoas físicas, seja na promoção das "externalidades positivas" ou "economias externas" — como um maior nível educacional ou científico, uma política monetária saudável ou o acesso a matérias primas importadas — que contribuem para a geração de valor "interno" aos agentes individuais da sociedade. ${ }^{9}$

Entretanto, do ponto de vista contábil-gerencial, ainda há poucos sistemas de informações econômico-financeiros dotados de instrumentos capazes de identificar nas organizações públicas, particularmente nas suas diversas atividades de regulação, fiscalização, controle, promoção, coordenação etc., o valor criado para a sociedade.

Essa questão será a seguir considerada à luz dos princípios e critérios do sistema de gestão econômica.

Dentro dos limites deste trabalho, será enfocado apenas o valor gerado por uma entidade ou organização pública para a sociedade, como contribuição desta organização para o valor total gerado pelo governo.

Não será examinada a implicação desse benefício na geração de valor pelo governo como um todo para a sociedade, nem a questão da valoração efetiva pela sociedade desses benefícios, uma vez que em ambas incidem outros e diversos parâmetros, cuja análise transcende os limites desta apresentação. ${ }^{10}$

\section{Gestão econômica de organizações governamentais}

\section{As organizações governamentais como sistemas de criação de valor}

A abordagem da gestão pública empreendedora parte de uma primeira questão: Que modelo de organização governamental melhor conduz à criação do valor? 
De fato, a capacidade de criação do valor depende em primeiro lugar da auto-identidade da própria organização, manifestada na sua missão, crenças e valores, objetivos e princípios de gestão, que podem propiciar, em maior ou menor grau, a gestão empreendedora e a criação de valor pela organização.

Como visto, uma das características da administração burocrática tradicional é a ênfase em uma visão linear e em procedimentos hierarquizados, estereotipados, gravados em muitos países por paradigmas autoritários: o funcionário público é predominantemente um cumpridor de ordens com pouca iniciativa. Como comenta Raymond Aron (1987: 320):

"Pensava Weber que a dominação burocrática caracteriza todas as sociedades modernas e constitui um setor importante de qualquer regime, mas o funcionário não foi feito para impulsionar o Estado (...) e sim para aplicar os regulamentos de acordo com os precedentes. Formou-se na disciplina, não na iniciativa (...)."

O perfil de uma organização empreendedora, ao contrário da visão linear tradicional, baseia-se na abordagem sistêmica que entende as organizações como conjuntos de elementos interdependentes que interagem entre si para a consecução de um fim comum, em constante interrelação com o ambiente (Ackoff, 1981: 29).

As organizações públicas, como sistemas abertos, integram-se no sistema governamental e da sociedade, mediante sua missão como razão de sua existência. Assim, o objetivo básico da organização governamental é cumprir sua missão em continuidade, criando valor para a sociedade. Para tal, a organização projeta objetivos, compartilhados por todos os níveis gerenciais, e interage continuamente com os sistemas da sociedade, dela captando os insumos e recursos de que necessita para a produção de bens e serviços que devolve à sociedade, com valor superior ao dos recursos recebidos.

No sistema organizacional, interagem subconjuntos de elementos, considerados como subsistemas. Como observa Guerreiro (1989: 154ss), a organização é constituída por pessoas (subsistema social), imbuídas dos princípios e valores organizacionais (subsistema institucional), que ocupam determinados postos com autoridade e responsabilidade prédefinidas (subsistema organizacional), as quais tomam decisões (subsistema de gestão) sobre recursos (subsistema físico), utilizando informações (subsistema de informação), para que a organização alcance os seus objetivos. Essas interações entre os diversos subsistemas da organização geram o ambiente organizacional capaz de converter a postura burocrática em postura empreendedora. Como comentam Osborne e Gaebler (1995:18): 
"Drucker afirma que praticamente qualquer pessoa pode ser um empreendedor, se a organização do processo produtivo for estruturada para encorajar a inovação. Inversamente, quase todo empreendedor pode se transformar num burocrata se essa organização for estruturada de modo a estimular a conduta burocrática."

Na ótica sistêmica da gestão econômica, cada organização governamental se estrutura e atua como um conjunto de áreas de responsabilidade, concebidas como criadoras de valor, como centros de resultado. Os gestores das áreas atuam como empreendedores dentro das suas respectivas responsabilidades, ou seja, como "donos" de suas atividades, em estreita coordenação com o todo da organização. De fato, o gestor é primeiramente um integrante da organização como um todo e só depois um gestor da sua própria área. Pela atuação integrada das áreas no conjunto da organização é criado um valor maior do que os valores que as áreas poderiam gerar se atuassem descoordenadamente. Assim, o valor é criado a partir dos centros de resultado, pela interação dos subsistemas organizacionais. ${ }^{11}$

\section{Identificação e mensuração do valor criado: o resultado da gestão pública}

\section{Resultados, índices \\ físicos e criação de valor}

$\mathrm{Na}$ avaliação das organizações públicas, é usual que resultados sejam definidos por indicadores físicos ou qualitativos. ${ }^{12}$ Tais critérios, entretanto, não são isentos de dificuldades. Valores, como por exemplo, kW/h e mortalidade infantil, são muitas vezes de natureza diversa e de difícil comparação. A aplicação de pesos e ponderações para se apurarem notas e ratings deixa largo espaço para arbitrariedades e pressões políticas. Merece um rating maior uma atividade que se destacou na geração de benefícios, mas necessitou de enormes subsídios? É bom ou mau desempenho atender a 5.000 famílias carentes a um custo de $\mathrm{R} \$ 50.000,00$ ?

Os inconvenientes dessa mensuração por índices físicos ou qualitativos, e por ponderação de pesos (Lima et al., 1999: 555), levantam a questão sobre a possibilidade de se abordar o resultado da gestão pública em parâmetros universais de expressão monetária de custos e benefícios, ou seja, em parâmetros econômicos de criação de valor.

Para a identificação do valor criado pela gestão pública, o ponto de partida é o conceito econômico de custo de oportunidade que compara o uso de um recurso com o seu melhor uso alternativo, na busca de se avaliar a melhor relação custo/benefício.

Como observa Oliveira (1999: 3): 
"Para que a mensuração econômica dessas atividades públicas seja válida, deve ser solucionada a questão dos custos de oportunidade (base para avaliação) desses serviços. (...) Uma atividade qualquer, desempenhada pelo Estado, tem um valor econômico correspondente à melhor alternativa disponível na sociedade para a obtenção de seu serviço. Esse valor seria o componente positivo do resultado da atividade — o de suas receitas."

Assim, se existe uma forma alternativa B de atender 5.000 famílias carentes com o custo de apenas $\mathrm{R} \$ 25.000,00 \mathrm{em}$ vez de $\mathrm{R} \$ 50.000,00 \mathrm{da}$ alternativa $\mathrm{A}$, considera-se que $\mathrm{A}$ gera um benefício que vale apenas $\mathrm{R} \$ 25.000,00$ (receita), a um custo de $\mathrm{R} \$ 50.000,00$, o que produz um resultado econômico negativo de $\mathrm{R} \$ 25.000,00$, o qual representa a expressão monetária do quanto foi má a decisão. Mantendo-se os mesmos parâmetros, uma organização governamental cujo recurso orçamentário é de $\mathrm{R} \$ 50.000,00$ e atende apenas 10.000 famílias, apresentará resultado zero. O resultado positivo só ocorre a partir deste mínimo. Se, por exemplo, forem atendidas 12.000 famílias, a receita será de $\mathrm{R} \$ 60.000,00$, com o custo de $\mathrm{R} \$$ 50.000,00, gerando-se um resultado econômico de $\mathrm{R} \$ 10.000,00$.

É desse modo possível mensurar-se economicamente o benefício gerado pela gestão pública como criação de valor. Essa mensuração não dispensa a necessidade de índices físicos e qualitativos, mas possibilita a sua comparação, mediante as respectivas expressões monetárias. ${ }^{13}$ A mensuração do valor criado possibilita ainda a otimização dos recursos disponíveis e a avaliação da atividade governamental pela sociedade como usuária dos serviços públicos e, simultaneamente, acionista ou dona da "coisa pública", em busca do melhor retorno dos recursos investidos via tributos.

\section{Critérios de mensuração}

O processo de gerenciamento requer a aplicação de medidas de quantidades, volumes, preços dos recursos, de bens e serviços e a sua comparação com outros bens e serviços no mercado, como parâmetros de criação do valor em qualquer atividade humana.

Os critérios de mensuração adotados na Gestão Econômica (GECON) derivam de três princípios básicos (Guerreiro, 1989: 184-225; Catelli, 1999, passim):

O valor é criado em cada transação. Por exemplo, em cada prestação de serviços, bem como em cada transação que contribui para a prestação de serviços.

A medida do valor é dada pelo mercado. Isso se refere, por exemplo, ao valor do dinheiro, ao valor do espaço ocupado pela organização, ao valor das horas de trabalho de cada integrante na organização e ao valor dos serviços produzidos. 
A criação do valor é identificada com a decisão que o produz. Com isso, o desempenho das diversas áreas e níveis de gestão baseia-se na sua efetiva contribuição para a criação do valor.

\section{Custo de oportunidade}

Como já mencionado, toda decisão que aplica recursos de natureza escassa em uma transação, com vista à criação de valor, por esse mesmo fato está excluindo a aplicação desse recurso em outra transação. Se eu preciso locomover-me, o custo de oportunidade da aquisição de um automóvel é o valor que eu poderia pagar pelo aluguel de um automóvel semelhante. Ou seja, pode-se dizer que o custo de oportunidade de um recurso com relação a uma decisão é o melhor uso do mesmo recurso em uma decisão alternativa.

O valor é criado quando um bem produzido ou um serviço prestado atinge um valor de mercado superior ao valor dos recursos consumidos. Para a caracterização do resultado econômico, é irrelevante que não haja e nem possa haver transação em dinheiro em troca do valor criado. O importante é que haja outros bens e serviços com valor de mercado que possam ser comparados com os bens e serviços criados pela organização. Assim, a receita é dada pelo melhor valor de mercado dos bens produzidos ou serviços prestados e o custo é dado pelo melhor valor de mercado dos respectivos recursos consumidos.

Por exemplo, o valor dos serviços educacionais prestados por uma escola pública gratuita tem como parâmetro de comparação o melhor valor de mercado praticado por escolas privadas para serviços similares. Essa comparação pode indicar ao gestor público as formas mais eficazes de se produzir um serviço para a sociedade.

Assim, o custo de oportunidade é de aplicação universal, desde que haja uma alternativa comparável para se obter o mesmo benefício ainda que este seja incomensurável (como o serviço do médico que salva uma vida ou os serviços de uma agência que regula e promove um grande setor da infra-estrutura econômica). Por isso, a consideração do custo de oportunidade possibilita identificar o impacto econômico de transações e serviços, em princípio de qualquer tipo de organização, inclusive não lucrativa e de qualquer esfera ou área governamental, desde que seja possível o benchmarking de outras iniciativas, serviços ou organizações similares. ${ }^{14}$

\section{Preços de transferência}

O conceito de custo de oportunidade também é importante para medir o valor criado nas transações internas entre áreas ou unidades de uma mesma organização. 
Por exemplo, a atividade de regulação de uma agência governamental envolve, entre diversas outras atividades, a de assessoria jurídica. Para se mensurar o valor desse serviço prestado à área de regulação, utiliza-se o preço de transferência, pelo qual a área de regulação "compra" os serviços de assessoria jurídica, pagando o preço de transferência, medido pelo custo de oportunidade, dado pelo menor valor de mercado da hora de uma assessoria jurídica equivalente. Assim, o preço de transferência, baseado no custo de oportunidade, possibilita identificar com precisão as receitas, custos e resultados de cada área de responsabilidade como se fosse uma organização dentro da organização.

Isso traz grandes vantagens para a avaliação do desempenho das áreas, identificando os impactos das decisões aos gestores que, efetivamente, tomaram e controlam-nas. Com isso, toda a organização se beneficia, aperfeiçoando seus processos internos, o que, em última análise, conduz à melhoria e aumento do valor por ela criado.

\section{Custeio direto}

A gestão econômica adota o método de custeio direto, considerando que o uso do rateio, embora freqüente, não se presta à identificação do valor criado em cada decisão, uma vez que apenas atribui um valor médio obtido por divisão matemática, sem se preocupar com o efetivo relacionamento entre os custos e as suas causas. Isso acarreta graves dificuldades na identificação dos resultados de cada área de responsabilidade, com impactos na avaliação de desempenhos.

Conforme o custeio direto, não existe resultado por unidade produzida, mas sim, margem de contribuição. No caso de uma agência governamental, a margem de contribuição, por exemplo, de um serviço de fiscalização é dada pela receita desse serviço (medida pelo custo de oportunidade do serviço alternativo existente no mercado) deduzida dos custos diretamente envolvidos no serviço de fiscalização. A contribuição da área de fiscalização é a soma da margem de contribuição de todos os serviços de físcalização prestados no período, deduzida dos custos fixos identificados com a área de fiscalização. O resultado da agência como um todo é o somatório das contribuições de todas as suas áreas, deduzido dos custos fixos identificados com a agência como um todo.

Do ponto de vista gerencial, o método do custeio direto é muito mais apropriado, porque evita que a gestão de uma determinada área seja penalizada por custos em que sua área não incorreu e sobre os quais não possui controle. Um sistema de gestão por resultados implica critérios de mensuração aptos a identificar receitas e custos apenas com as áreas e decisões que os originaram, evitando-se todo rateio. 


\section{Equivalência de capitais e moeda constante}

A gestão pública empreendedora otimiza recursos financeiros mediante equivalência de capitais e moeda constante. São assim considerados os juros presentes em transações que envolvem prazos. Todos os valores são mantidos e comparados em moeda de mesmo poder aquisitivo, deduzido o efeito da inflação na moeda.

\section{Os sistemas de gestão e de informação da organização pública empreendedora ${ }^{15}$}

Com vista à criação de valor para a sociedade dentro de sua missão, a organização pública empreendedora decide continuamente o melhor emprego de seus recursos mediante o planejamento estratégico, o planejamento operacional, a execução e o controle, no processo de gestão de suas atividades, como ilustrado na Figura 1 (adaptada de Catelli, 1999:286).

Embora essas fases se estendam no tempo, de fato, trata-se de um processo interativo, que abrange cada ação e decisão relevante da organização e envolve a atuação pró-ativa de cada gestor, conforme a visão sistêmica da organização empreendedora. Cada gestor, dentro de sua área de responsabilidade, gerencia todas as suas ações, planejando-as dentro da estratégia e planos da organização, executando-os conforme o planejado e comparando o realizado com o planejado. Com isso controla a ação, a fim de antecipar e corrigir eventuais desvios ou inadequações. O desempenho das diversas áreas e seus gestores é, por sua vez, avaliado no processo de gestão global da organização.

No planejamento estratégico, são fixados os grandes objetivos e as diretrizes gerais que permitirão à organização governamental atuar no ambiente, segundo sua missão, crenças e valores e dentro das expectativas da sociedade, do governo e do setor em que atua. Essa visão estratégica integra todos os níveis gerenciais de modo a gerar a coesão e o impulso motivador necessários para a atuação empreendedora. Nessa fase, não há ainda destinação de recursos nem resultados mensurados, mas as estratégias se desenvolvem, em diálogo com a autoridade superior, sobretudo com vista a contratos de gestão.

Orientada pelas diretrizes estratégicas do plano estratégico e acordadas no seu contrato de gestão, a organização desenvolve os seus planos operacionais de ação de forma a otimizar a criação de valor a partir dos recursos disponíveis ou aos quais tenha acesso. São nessa fase definidas metas operacionais quantificadas, bem como os prazos para o seu cumprimento. A partir dessas metas, são analisadas as diversas alternativas de 
ação, escolhendo aquelas que possibilitem a criação otimizada do valor.

Definem-se, assim, os bens e serviços a serem gerados pela organização, quanto ao seu volume, características, tipos de usuários e efeitos específicos pretendidos, estimando-se o valor a ser criado por esses bens e serviços, em comparação com seus custos.

Figura 1: O sistema de informação no processo de gestão de uma organização

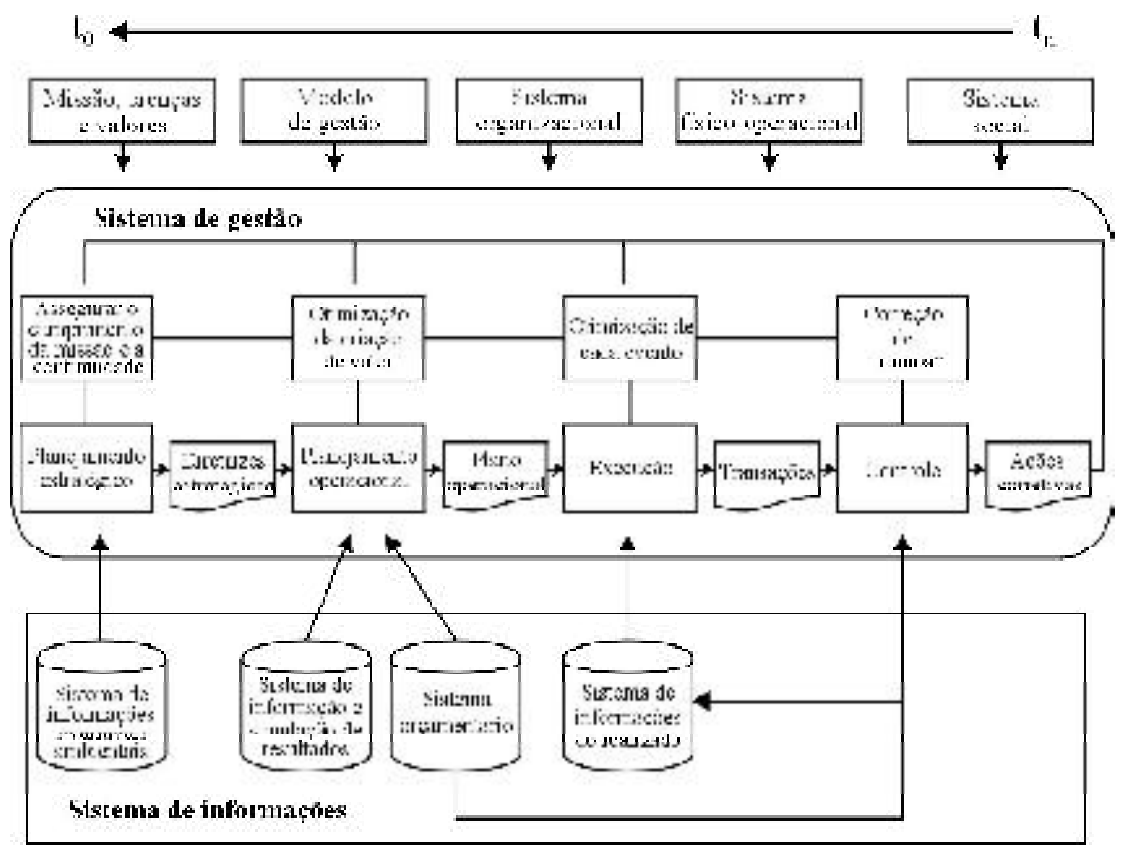

Nessa fase, o sistema de informação atua proporcionando simulações das diversas aplicações possíveis dos recursos, com vista à criação otimizada de valor, a fim de que seja elaborado o melhor plano de ação e o melhor orçamento possível. Para isso, o sistema detecta e fornece os padrões físicos de recursos necessários para cada tipo de serviço, subprocesso e área da organização, bem como os seus preços. Os volumes dos diversos serviços são projetados pelos respectivos gestores e lançados no sistema.

Um dos critérios da boa prática orçamentária ${ }^{16}$ — sobretudo quando uma postura empreendedora se defronta com regulações ainda muito burocratizadas - é constituir rubricas ou contas no orçamento global da organização que, por um lado, propiciem o controle preciso e burocrático dos recursos e, ao mesmo tempo, possibilitem aos diversos gestores o espaço de atuação necessário à criação do valor no âmbito de cada área de responsabilidade. Com isso, busca-se a solução de um duplo problema na gestão pública: como formalizar projeções e controles com valor legal 
dentro do sistema governamental e como gerenciar a organização para otimizar recursos e criar valor para a sociedade.

Elaboram-se, assim, conforme a Figura 2, o chamado orçamento formal ou público, que abrange todas as suas contas globais, e o orçamento gerencial, que define como os recursos previstos nas contas globais serão melhor aplicados nas ações concretas das diversas áreas de responsabilidade.

\section{Figura 2: Orçamento gerencial e orçamento público}

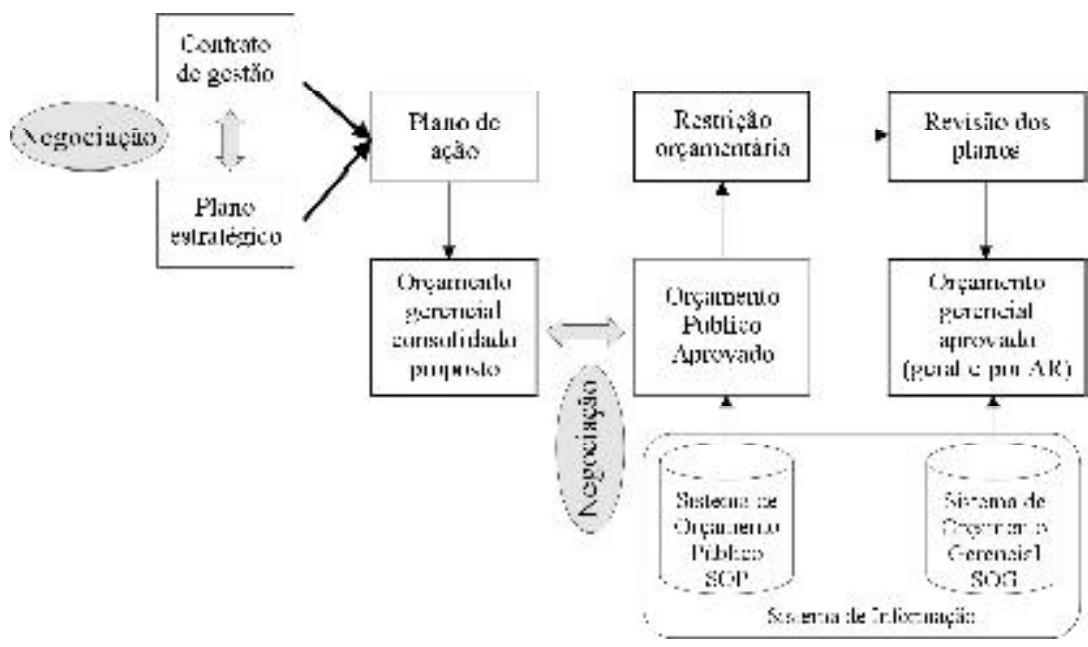

O orçamento gerencial, ao possibilitar a demonstração do valor a ser criado pela aplicação dos recursos, não apenas justifica os recursos pretendidos, mas dimensiona o seu retorno em valor para a sociedade, podendo ensejar, inclusive, aumentos nos recursos pretendidos, com vista ao valor adicional a ser criado. Essa abordagen é expressa por duas formatações do sistema de informação:

- a abordagem gerencial (com seus respectivos planos de contas, critérios de mensuração etc.) é apresentada pelo Subsistema de Orçamento Gerencial (SOG);

- a abordagem do orçamento público (conforme os planos de contas e critérios prescritos pelo orçamento público) é apresentada pelo Subsistema de Orçamento Público (SOP) do sistema de informação.

Após a aprovação do orçamento da União e conforme as suas restrições ao orçamento proposto, o orçamento gerencial da organização e das áreas é reajustado, conforme as restrições sofridas, convertendo-se no orçamento gerencial aprovado. Para a prestação de contas à entidade controladora, os dados do SOG são novamente transpostos para a formatação do SOP. 
A execuçãoé a fase mais importante do processo de gestão, considerando-se a freqüência com que os planos, em todos os tipos de organização, deixam de ser cumpridos ou sofrem grandes desvios durante a sua concretização. A execução é que dá sentido e realidade ao planejamento. Este, sem a execução, é apenas um sonho ou um álibi, como sucede muito freqüentemente. É na execução que a organização mostra efetivamente sua disposição pró-ativa de realizar ou fazer e de gerar valor.

O controle é a reflexão contínua da organização sobre a sua própria atividade para verificar até que ponto suas ações estão efetivamente atingindo os seus objetivos, ou seja, até que ponto a organização está sendo eficaz, obtendo resultados.

A manutenção dos dois subsistemas orçamentários — o orçamento público e o orçamento gerencial — permite à organização pública abordar os aspectos de prestação de contas dos gastos conforme as dotações orçamentárias aprovadas pelo governo controlador e avaliar a sua eficácia na criação de valor. $\mathrm{O}$ orçamento gerencial permite, a partir da comparação com os resultados realizados, verificar os desvios por área de responsabilidade, avaliando a gestão da organização, não apenas quanto às entradas — ou seja, quanto à legitimidade dos gastos efetuados — mas também quanto às saídas - ou seja, quanto ao valor efetivamente gerado pela organização para a sociedade.

\section{Considerações finais}

A difícil busca da eficácia na gestão da coisa pública - uma aspiração básica de todas as sociedades em todos os tempos — terá dado um passo adiante com o advento recente do "governo por resultados".

Mas, a geração de resultados por uma gestão pública empreendedora só pode ser alcançada na medida em que as organizações públicas, superando os limites tradicionais da administração burocrática, desenvolvam modelos de gestão capazes de fazer interagir simultaneamente sistemas e pessoas com autonomia e coordenação, iniciativa e controle.

A avaliação dos resultados efetivamente obtidos nas organizações governamentais empreendedoras demanda conceitos de mensuração que permitam identificar a criação de valor nas suas várias atividades e áreas e nas diversas decisões que constituem o seu contínuo e interativo processo gerencial.

Os critérios e princípios de gestão econômica das organizações governamentais oferecem instrumentos gerenciais demandados pela gestão pública empreendedora, possibilitando simultaneamente a prestação de contas ao controlador governamental, o gerenciamento eficaz, voltado à criação de valor, e a comunicação do valor gerado à sociedade, para sua avaliação como usuária e dona da coisa pública. 


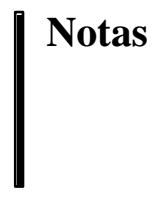

1 Este trabalho foi apresentado no VII Congresso Internacional do Instituto Internacional de Custos realizado juntamente com o II Congresso Asociación Española de Contabilidade Directiva (ACODI) em León, Espanha, em julho de 2001. Para sua publicação no Brasil foram efetuadas algumas complementações e atualizações visando melhor foco e contextualização do tema.

2 Macpherson (1973: 189) observa que os conceitos econômicos de mercado são aplicáveis às políticas das sociedades democráticas prósperas ou otimistas - o que hoje incluiria não apenas a América do Norte, Europa Ocidental e Japão, mas também os países emergentes da América Latina, da Ásia e da Europa Oriental.

3 A Gestão Econômica (GECON) é um modelo gerencial de vanguarda, criado por Armando Catelli e desenvolvido por uma equipe de pesquisadores da FEA/USP, implantado em grandes empresas do país, bem como em organizações governamentais, que compreende um sistema de gestão e um sistema de informação voltados para a eficácia das organizações. Ver Catelli, 1999. (www.gecon.com.br).

4 Ver a esse respeito Presidency of the Republic, 1995: 20 ss. (Bresser Pereira, 2000: 16-19).

5 "Vilfredo Pareto formulou o que hoje é conhecido como Lei de Pareto. Após toda uma vida estudando a distribuição da renda, Pareto concluiu que o governo é incapaz de efetivamente modificá-la. A distribuição de renda, influenciada apenas marginalmente pelos costumes e valores locais, é determinada pela produtividade de uma economia. Quanto menos produtiva, maior a desigualdade de rendas; quanto mais produtiva, menor a desigualdade" (Drucker, 1989: 59).

6 A gestão pública empreendedora não visa, porém, eliminar, mas sim renovar os princípios da administração burocrática. Adotar "princípios de gestão de negócios" na nova gestão pública não significa "governar como quem dirige uma empresa". As empresas, com efeito, têm interesses particulares e visam lucro a partir dos preços de venda de seus produtos e serviços, ao contrário das organizações públicas, as quais não vendem seus serviços, visam sempre o bem comum, sem fins lucrativos, e têm por receitas os impostos obrigatoriamente coletados da sociedade (Osborne e Gaebler, 1995: 21ss; Presidency of the Republic, 1995: 22; Bresser Pereira, 2000: 24).

7 Sobre contratos de gestão ver, por exemplo, Johnson et al., (1996); Ramos (1997); Bresser Pereira (2000:22) ; Lima, (1999).

8 Sobre o "modelo de agências" no "Estado regulador", ver por exemplo Majone (1999).

9 Sobre o conceito de "externalidades" na literatura, ver Mishan (1971: 1-27) e Torres (1998); sobre a relação entre externalidades e reforma gerencial do Estado no Brasil, ver menções de Bresser Pereira (2000: 19-21). Sobre governo e fatores da vantagem competitiva nacional, ver por exemplo Porter (1993: 146ss).

${ }^{10}$ É de notar que a gestão econômica estuda esses três enfoques do valor - para uma organização pública, para o governo como um todo e para a sociedade - considerando, de modo semelhante ao que ocorre nas empresas, que um produto ou serviço pode ter um valor final ou custo de oportunidade A para a unidade produtora, um valor B para o conjunto da corporação e valores diferenciados $\mathrm{C}_{1}, \mathrm{C}_{2} \ldots \mathrm{C}_{\mathrm{n}}$ para cada cliente ou usuário que o adquire (Catelli, 2000). Este tema será publicado em outro trabalho, ora em elaboração.

${ }^{11}$ Ver Catelli (1999) e Santos e Ponte (1998).

${ }^{12}$ Ver a esse respeito - além das obras citadas de Osborne (1994) e Osborne e Gaebler (1995) —, também Graham Jr. e Hays (1994), Mitchell e Harrison (1991), Lane (1995), Light (1995), Teixeira e Santana (1994) entre outros. 
${ }^{13}$ A expressão da relação entre eventos físicos e conceitos econômicos é central na abordagem do sistema de informação de gestão econômica e se aplica a qualquer organização, como observa Guerreiro (1989: 25-26).

${ }^{14}$ Sobre as diferenças na consideração da relação custo-benefício por parte das empresas e das organizações governamentais, ver as observações de Campos et al., (2000: 39s).

${ }^{15}$ Sobre o processo de gestão e o sistema de informações gerenciais, ver Catelli (1999: 127-146).

${ }^{16}$ Sobre os diversos enfoques de orçamentos nas organizações públicas, ver Jones e Thompson (2000: $68 \mathrm{ss)}$.

\section{|| Referências bibliográficas}

AcкоғF, Russel L. (1981), Creating the corporate future. New York: John Wiley.

AlmeidA, Lauro B. (1996), "Estudo de um modelo conceitual de decisão, aplicado a eventos econômicos, sob a ótica da gestão econômica". Dissertação (Mestrado) — FEA/USP. São Paulo.

Aron, Raymond. (1987), As etapas do pensamento sociológico, 2a edição. São Paulo: Martins Fontes.

BARBOSA, L. (1996) “Meritocracia à brasileira: o que é desempenho no Brasil?”, Revista do Serviço Público - RSP/ENAP. 47 (3), set.-dez., pp. 59-101.

Bresser Pereira, L. C. (1999), Reforma do Estado para a cidadania. São Paulo: Ed. 34. . (1998), "Reflexões sobre a reforma gerencial brasileira de 1995". Revista do Serviço Público - RSP/ENAP. 50 (4), out.-dez.

. (2000), "A reforma gerencial do Estado de 1995". Revista de Administração Pública - RAP/FGV. 34 (4), jul.-ago., pp. 7-26.

CAmpos, A. M. et al., (2000), "Avaliação de agências reguladoras: uma agenda de desafios para a sociedade brasileira". Revista de Administração Pública - RAP/FGV. 34 (5), set.-out., pp. 29-46.

Catelli, Armando. (1999), Controladoria: uma abordagem da Gestão Econômica GECON. São Paulo: Atlas.

(2000), Avaliação da gestão pública. Palestra apresentada no Seminário ESAF 25 anos. São Paulo. Não publicado.

CATELli, Armando. (2001), Gestão econômica de organizações governamentais, in Anales del Séptimo Congreso Internacional Del IIC y II Congreso-ACODI 2001. Léon, Espanha, jul.

Coutinho, M.J.V. (2000), "Administração pública voltada para o cidadão: quadro teóricoconceitual". Revista do Serviço Público - RSP/ENAP. 51 (3), jul.-set., 2000, pp.41-74.

DruckER, Peter F. (1978), The age of descontinuity. New York: Harper Colophon Books. . (1991), As novas realidades. Tradução de Carlos Afonso Malferrari. 2a edição. São Paulo: Pioneira.

(1992), Administrando para o futuro. Tradução de Nivaldo Montingelli Jr.

São Paulo: Pioneira.

FALCO, S.E. (2000), "Instrumentos de voice giving na relação entre os cidadãos e a administração pública: a carta dos serviços". Revista do Serviço Público-RSP/ENAP 51 (3), jul.-set., pp. 5-27.

Freitas, C.A.S. (1999), “A implementação do Governance Performance and Results Act na administração pública dos EUA". Revista do Serviço Público — RSP/ENAP 50 (3), jul.-set., pp.93-122. 
Graham Jr., Cole B., Hays, Steven W. (1994), Organização pública. Tradução de Britta L. de Freitas.Rio de Janeiro: Jorge Zahar Ed.

Guerreiro, Reinaldo. (1989), "Modelo conceitual de sistema de informação de gestão econômica: uma contribuição à teoria da comunicação da contabilidade". Tese (Doutorado) — FEA/USP. São Paulo.

Jones, L. R., Thompson, F. (2000), "Um modelo para a nova gerência pública". Revista do Serviço Público - RSP/ENAP. 51 (1), jan.-mar., pp. 41-75.

Lane, Jan-Eirik. (1995), The public sector. London: Sage Publications.

Light, Paul C. (1995), Thickening government. Washington: The Brookings Institution e The Governance Institute.

Lima, Iran S. et al. (1999), "Contrato de Gestão: uma solução para as estatais brasileiras", in CAtelli, Armando, Controladoria: uma abordagem de Gestão Econômica - GECON. São Paulo: Atlas.

M acPherson, C. B. (1990), Democratic theory: essays in retrieval. New York: Clarendon Press. Marshall, Alfred. (1996), Princípios de economia: tratado introdutório. Tradução de Rômulo Almeida e Ottolmy Strauch. São Paulo: Nova Cultural.

Mishan, E. J. (1971), “The postwar literature on externalities: an interpretative essay". Journal of Economic Literature. mar., p.1-28.

Mitchell, Bob; Harrison, John. (1991), Public administration. London: Pitman Publishing.

Oliveira, Antônio B. S. (1999), A atividade social e seu valor econômico. São Paulo, (www.gecon.com.br).

Osborne, David; Gaebler, Ted. (1995), Reinventando o governo. Tradução de Sérgio Fernando G. Bath e Ewandro M. Júnior; 6a edição. Brasília, MH Comunicação.

Osborne, David. (1994), Laboratories of democracy. Boston: Harvard Press.

PARISI, Cláudio. (1999), "Uma contribuição ao estudo de índice interno de preços sob a ótica da Gestão Econômica”. Tese (Doutorado) — FEA/USP. São Paulo.

Pigou, A. C. (1962), The economics of welfare. London: Macmillan.

Porter, Michael E. (1993), A vantagem competitiva das nações. Tradução de Waltensir Dutra. Rio de Janeiro, Campus.

Presidency of the Republic. (1995), White paper reform of the state apparatus. Brasília.

Ramos, M. M. (1999), "Contratos de gestão: instrumento de ligação entre os setores do aparelho do Estado”. Revista do Serviço Público — RSP/ENAP 48 (2), mai.-ago., pp. 81-100.

SAntos, Edilene S. (2000), "Gestão integrada de estratégias e operações: uma abordagem de gestão econômica”. Dissertação (Mestrado) — FEA/USP. São Paulo.

Santos, Edilene S., Ponte, Vera. (1998), Gestão Econômica: um modelo para integração sistêmica da empresa, in Congresso Brasileiro de Gestão Estratégica de Custos, V. v.2, pp. 705-721. Fortaleza, set.

Teixeira, H. J., Santana, S. M (coords.). (1994), Remodelando a gestão pública. São Paulo: Edgard Blücher.

Thoenig, J.C. (2000), “Avaliação como conhecimento utilizável para reformas de gestão pública”. Revista do Serviço Público — RSP/ENAP 51 (2), abr-jun, 2000, pp. 55-72.

Torres, Marcelo O. (1998), "Políticas ambientais de second best: alternativas às políticas de Pareto ótimas de internalização de externalidades”. Dissertação (Mestrado) — FEA/USP. São Paulo. 


\section{Resumo \\ Resumen \\ Abstract}

\section{Um sistema para a gestão econômica de organizações governamentais empreendedoras}

Armando Catelli, Cláudio Parisi, Edilene Santana Santos e Lauro Brito de Almeida

Este trabalho aborda a tendência atual em diversos países, inclusive no Brasil, para uma gestão pública empreendedora, como criadora de valor para a sociedade. Implicações dessa nova postura para o sistema de informações econômico-financeiras são tratadas à luz dos princípios e critérios do sistema de gestão econômica. Primeiramente é considerado o modelo de organização governamental próprio para a superação da postura burocrática tradicional pela postura empreendedora. A criação de valor nas atividades da organização pública e os critérios econômicos de mensuração dos resultados são, a seguir, examinados. Aborda-se, finalmente, o impacto da postura empreendedora no processo de gestão e no sistema de informação de uma organização governamental, tendo em vista, por um lado, o relacionamento legal da organização com a autoridade superior e, por outro, as necessidades do gerenciamento da criação de valor para a sociedade.

\section{Un sistema para la gestión económica de organizaciones públicas emprendedoras}

\section{Armando Catelli, Cláudio Parisi, Edilene Santana Santos y Lauro Brito de Almeida}

Este trabajo plantea la tendencia actual en diversos países, inclusive en el Brasil, para una gestión pública emprendedora y creadora del valor para la sociedad. Las implicaciones de esa nueva postura para el sistema de información económico-financiera son tratadas a la luz de los principios y criterios del sistema de gestión económica. Primeramente se considera el modelo de una organización de gobierno propia para la superación de la postura burocrática tradicional por la postura emprendedora. En seguida se examina la creación del valor en las actividades de las organizaciones públicas, conforme a los criterios económicos de medición de sus resultados. Finalmente el artículo aborda el impacto de la postura emprendedora en el proceso de gestión y en el sistema de información de una organización de gobierno, considerando por una parte, las relaciones legales de la organización con la autoridad superior y, por otra, las necesidades de la gestión en la creación del valor para la sociedad.

\section{A system for economic management of entrepreneurial governmental organizations}

\section{Armando Catelli, Cláudio Parisi, Edilene Santana Santos and Lauro Brito de Almeida}

This work approaches the present tendency in several countries, including Brazil, towards an entrepreneurial public management creating value to society. The implications of this new posture for the economic financial information system are addressed in the light of the principles and criteria of the economic management system (sistema de gestão econômica). First it is considered the appropriate model of a governmental organization surpassing traditional bureaucratic posture by the entrepreneurial posture. Value creation in the public organizations' activities and the economic criteria for measuring results are then examined. Finally the article discusses the impact of the entrepreneurial posture on the managing process and on the financial information system of a governmental organization, considering the legal relationships between the organization and its superior authorities and, on the other hand, the needs arising from managing value creation to society.
Revista do

Serviço

Público

Ano 52

Número 3

Jul-Set 2001

Armando Catelli é professor-doutor dos Programas de Mestrado e

Doutorado em

Controladoria e

Contabilidade da FEA-USP.

Cláudio Parisi é mestre e doutor em Controladoria e

Contabilidade pela FEA-USP e professor da FECAP.

Edilene Santana Santos é mestre e doutoranda em Controladoria e Contabilidade pela FEA-USP e pesquisadora da FIPECAFI.

Lauro Brito de Almeida é mestre e doutorando em Controladoria e Contabilidade pela FEA-USP. 